\section{Hygiene and welfare evaluation of pigs slaughtered in agritourisms}

\author{
Rina Mazzette, ${ }^{1}$ Francesca Piras, ${ }^{1}$ \\ Vanessa Agus, ${ }^{1}$ Gabriella Porcheddu, \\ Giuseppe Fois, ${ }^{2}$ \\ Simonetta Gianna Consolati ${ }^{1}$ \\ 'Department of Veterinary Medicine, \\ University of Sassari; ${ }^{2}$ Local Health Unit \\ n.1, Sassari, Italy
}

\section{Abstract}

The slaughtering procedures at agritourism farms must be carried out in accordance with the general and hygiene requirements of Regulations (EC) No 852 and 853/2004. In addition, regional laws define minimum requirements allowing some flexibility. Piglets and finishing pigs are the most frequently slaughtered animal in Sardinian agritourism farms. The aim of the present survey was to evaluate: the general and hygiene requirements of outbuilding slaughterhouses in agritourisms; the animal welfare indicators; the microbial contamination of piglets and finishing pigs carcasses. Six agritourisms outbuilding slaughterhouses - EU-approved - were investigated. General and hygiene requirements of outbuilding slaughterhouses and animal welfare indicators of 68 piglets and 5 finishing pigs were evaluated by mean of a checklist. The following parameters were determined on 45 piglets and 5 finishing pigs carcasses: i) $\mathrm{pH} 1$ and $24 \mathrm{~h}$ after slaughter, and ii) carcass surface microbial contamination by non destructive method (sponge) on the following sampling sites: ham; back (adults); belly; jowl (adults). Aerobic colony count (ACC; ISO 4833:2003), Enterobacteriaceae (EB; ISO 21528-2:2004), Salmonella spp. (ISO 6579:2002), Listeria monocytogenes (IS0 11290-1:1996 and 11290-2:1998) were also tested. All the plants except one have two separate rooms, for clean and dirty zones, stunning and bleeding operations being frequently carried out on open air. The piglet scalding was carried out in hot water bowls, and hair removal by singeing. Animal welfare signs revealed the following aspects: handling: hoisting prior to stunning, vocalizations (41\%); stunning: not individual access to box, repeated shocks (4\%), mean voltage $135.6 \mathrm{~V}$, mean current for head-only electrical stunning $0.78 \mathrm{~A}$; indicators of not effective stunning: palpebral reflex (24.2\%), corneal reflex (12.8\%), vocalizations (15.4\%); bleeding: conscious and sensitive animal shackling (53.8\%). Results of carcass evaluation showed, for piglets and adult pig respectively: i) $\mathrm{pH}: \mathrm{pH} 1=6.21 \pm 0.25$ and $6.18 \pm 0.22 ; \mathrm{pH} 24=5.66 \pm 0.17$ and $5.49 \pm 0.11$; ii) ACC: $4.11 \pm 0.64$ and $4.63 \pm 0.42\left(\log _{10} \mathrm{CFU} / \mathrm{cm}^{2}\right.$, mean \pm standard deviation); iii) Enterobacteriaceae prevalence of $81.6 \%$ $(2.55 \pm 0.80)$ in piglets and $100 \%(3.22 \pm 0.90)$ in adults. Salmonella spp. and Listeria monocytogenes were not detected in any of the samples. General requirements of outbuilding slaughterhouses in agritourisms are suitable to produce meat in compliance with hygienic rules, considering the low risk level. Results of Enterobacteriaceae levels of finishing pig carcasses were not in compliance with the EC Regulation No 2073/2005. Training of personnel is compulsory and can improve the stunning and bleeding procedures.

\section{Introduction}

The agritourism can be considered as a form of sustainable rural exploitation. Even though there is no specific legislation on agritourisms in Europe, regulations that give to Member States the authority to assign economic resources to rural exploitation are in force. The most recent is EC Regulation 1305/2013 (European Commission, 2013) that lays down general rules governing Union support for rural development, financed by the European Agricultural Fund for Rural Development (EAFR). In Italy, the agritouristic activity is regulated by the framework law n.96/2006 (Italian Republic, 2006) that indicates to Regions the general principles and criteria to practice this kind of activity. The regulatory framework in the different Italian regions is highly different, both as regard the aspects that are regulated and the time of issuing. In Italy, agritourisms are largely widespread (over 20,000), especially in the north-west and center regions. The most part produce meat for human consumption in small local slaughterhouses, in accordance with the general and hygiene requirements set by Regulations (EC) No 852 and 853/2004 (European Commission, 2004a, 2004b), amended according to the flexibility concept and regional laws. The flexibility concept is intended to guarantee the food safety to the consumers, without compromising the general aims of food hygiene. The flexibility concept is interpreted in different ways, and therefore not homogeneously applied, in relation to the different animals slaughtered, depending on the specie reared at the farms. In Sardinia, the regional law n.18/1998 (Sardinia Region, 1998) defines criteria for agritouristic activity. Comma 7 of the regional law n.18 establishes that slaughtering of animals at agritourisms is allowed, by derogation of the existing laws, next to polyfunctional premises. These regional rules state the annual
Correspondence: Rina Mazzette, Department of Veterinary Medicine, Sector of Inspection of Food of Animal Origin, University of Sassari, via Vienna 2, 07100 Sassari, Italy.

Tel: +39.079.229452 - Fax: +39.079.229458.

E-mail: rmazzett@uniss.it

Contributions: RM, data collecting and manuscript writing; FP, data collecting and manuscript reviewing; AV, GP, SGC, data collecting and analysing; FG, manuscript reviewing.

Conflict of interest: the authors declare no potential conflict of interest.

Received for publication: 16 July 2014.

Revision received: 9 December 2014.

Accepted for publication: 9 December 2014.

This work is licensed under a Creative Commons Attribution 3.0 License (by-nc 3.0).

(C) Copyright R. Mazzette et al., 2015

Licensee PAGEPress, Italy

Italian Journal of Food Safety 2015; 4:4580

doi:10.4081/ijfs.2015.4580

capacity of agritourism and the simplified requirements for slaughter. In Sardinia, mainly swines (both finishing pigs and piglets), sheep and goats are slaughtered at agritourisms. As regard to animal welfare, slaughtering at agritorisms must be carried out in accordance with EC Regulation 1099/2009 (European Commission, 2009).

Few studies on meat production and slaughtering at agritourism level are available. However, a comparison can be made with studies carried out at slaughterhouse both on hygiene (Zweifel et al., 2008; McDowell et al., 2007) and on welfare (Sejian et al., 2011) indicators.

The aim of the present survey was to evaluate the general and hygiene requirements of outbuilding slaughterhouses in agritourisms in Sardinia. The animal welfare signs and the microbial contamination of piglets and finishing pig carcasses were also evaluated.

\section{Materials and Methods}

The survey was carried out at outbuilding slaughterhouses in 6 agritourisms (A1, A2, A3, A4, A5, A6), EC approved according to EC Reg. n. 853/2004 (European Commission, 2004b), Annex III, Section I, to slaughtering finishing pigs and piglets. Each slaughterhouse was visited two times. During the visits, piglets (about 30-45 days old) and finishing pigs (7-8 months old) were slaughtered. The following activities were carried out: i) evaluation of structural and hygienic requirements of premises and 
slaughtering operations; ii) animal welfare evaluation; iii) carcass evaluation.

As for the evaluation of structural and hygienic requirements of premises and slaughtering operations, the following information was collected by mean of a check-list: general information about the agritourism (number of operators; slaughtered species; slaughtered heads/year; slaughtering days/week) and [structural characteristics of premises and equipment: lairage; separation of the clean and the dirty zone; characteristics of the surfaces (walls and floor); installations that prevent contact between the meat and the floors, walls and fixtures; slaughtering operations; facilities for disinfecting tools; refrigeration facilities, by-products storage system].

As for the animal welfare evaluation, 73 pigs (68 piglets, and 5 finishing pigs) were evaluated by mean of a check-list built according to the EC Regulation 1099/2009 (European Commission, 2009), on the protection of animals at the time of killing, EFSA opinion on monitoring procedures at slaughterhouses for bovines (2013) and the Recommended Animal Handling Guidelines \& Audit Guide (Grandin, 2013). By mean of the checklist the following aspects were evaluated: unloading [unloading time; ramp characteristics, pigs behaviour during unloading (e.g. slipping/falling)]; handling procedures; restraint procedures before stunning; stunning procedure [entrance of the pigs in the stunning area; stunning method (electrical or penetrative captive bolt device); state of maintenance of stunning equipment; in case of electrical stunning: current (A) and voltage $(V)$ measured at the electrodes; checks of effectiveness of stunning to ensure that the animals do not present any signs of consciousness or sensibility in the period between the end of the stunning process and death (righting reflex, head circle movements, eye movements, corneal reflex, eye vibration, vocalizations, uncoordinated kicking of hind legs, absence of breathing); time between stunning and bleeding].

As for the carcass evaluation, analyses were performed on 45 piglets (about 30-45 days old, 10-15 kg live weight) and 5 finishing pigs (7-8 months old, 100-120 kg live weight). Piglets carcasses were evaluated at slaughterhouses A1, A2, A3, A4 and A5. Finishing pigs carcasses were evaluated at $\mathrm{A} 3$ and $\mathrm{A6}$. Carcass $\mathrm{pH} 1$ and $24 \mathrm{~h}$ after slaughtering was made by using a portable pH-meter (Crison GLP21, Crison Instruments) in $M$. longissimus dorsi. During the 24 hours after slaughtering, carcasses were stored in cold stores with controlled temperature $\left(+2 \pm 2^{\circ} \mathrm{C}\right)$. Carcasses were sampled after evisceration and before chilling by sponge, according to ISO 17604 and Reg. EC 2073/2005 (ISO, 2003b; European Commission, 2005) at ham, back (adults), belly and jowl (adults) site. Sponges were analysed for the following microrganisms: aerobic colony count (ACC; ISO 4833:2003; ISO, 2003a); Enterobacteriaceae (EB; ISO 21528-2:2004; ISO, 2004); Salmonella spp. (IS0 6579:2002; ISO, 2002); Listeria monocytogenes (ISO 11290-1:1996 and 11290-2:1998; ISO, 1996, 1998).

\section{Results}

\section{Evaluation of structural and} hygienic requirements of premises and slaughtering operations

Farms of origin of the animals are at a maximum distance of $0.5 \mathrm{~km}$ from the agritourisms and their outbuilding slaughterhouses. Therefore, animals were moved just few minutes before slaughtering and there were not lairages at slaughterhouses. Piglets were moved inside wagons pulled by one operator with a farm tractor. The wagons were not covered as the distance was very short. A maximum of 10 piglets, belonging to the same pen, was transported inside each wagon. Finishing pigs were moved individually by walking and induced by mean of feed by the operator. All the plants (except for A4) have two separate rooms, for clean and dirty zones. The dirty zone of Al and A5 are outside, covered and closed by walls. A4 has got only one room and stunning and bleeding operations are carried out in the open air. All the plants are provided with surfaces (floors and walls) easy to clean and disinfect, facilities for disinfecting tools with hot water, installations (hooks) that prevent contact between the meat and the floors, walls and fixtures, refrigeration facilities, bins for by-products storage, Stomachs and intestines are not submitted to further handling but are stored in a dedicated fridge with by-products and collected by an external company for disposal. The official veterinarian carried out the ante-mortem inspection. Each pig (both piglets and finishing pigs) was slaughtered following the same procedures: stunning, jugulation, bleeding, scalding, dehairing, flaming, polishing, evisceration, splitting of carcass (only for finishing pigs), veterinary inspection and chilling. During stunning, piglets were constraint manually while for finishing pigs a restraining equipment (wagon) was used. The electrical (head-only) stunning was used for piglets, the mechanical method (penetrative captive bolt device) for finishing pigs. The scalding procedures were carried out in hot water (in bowls for piglets and tank for finishing pigs). The water temperature was comprised between +58 and $+62^{\circ} \mathrm{C}$. Water was never changed between animals, but it should be considered that a maximum of 10 piglets and 2 finishing pigs per time, were slaughtered. Dehairing was performed manually and then carcasses were scalded by a direct flame. After evisceration, the official veterinarian carried out the post-mortem inspection.

\section{Animal welfare evaluation}

The animals were not inspected by animal welfare officers. Before unloading, piglets were constraint inside wagons for a period usually lower than $15^{\prime}$ (48\%), up to a maximum of 30'. The monitoring of handling/restraint showed: hoisting by legs prior to stunning, in particular in piglets (100\%); a high prevalence (41\% in adults, and $95.9 \%$ in suckling pigs) of vocalizing animals. During unloading, no animal slipped or fell, no animal was injured or died. Most of the piglets (53\%) were manually hanged to stunning. Stunning procedures were not carried by trained operators. The monitoring of stunning showed: not individual access for the $22 \%$ of the animals and no measures to prevent the vision of stunning operations for $14.7 \%$ of the piglets. The equipments (electrical tongs and penetrative captive stunner) presented appropriate size, good hygiene and maintenance conditions. There were no devices to be used in case of non-operating equipments. The electrodes were applied incorrectly for the $23.5 \%$ of piglets, on the cheeks or on the lateral part of the neck; as a result, in some cases (4\%) repeated shocks had to be applied. In all slaughterhouses the display for monitoring the stunning parameters was present, but a recording system was not in place. The mean current registered for electrical stunning was $0.78 \pm 0.51 \mathrm{~A}$ (range $0 \rightarrow 1.9$ ), and the mean voltage was $135.6 \pm 17.31 \mathrm{~V}$ (range $121 \rightarrow 185$ ); the exposure time ranged from 2" to 8 ". The checks of effectiveness of stunning showed: one piglet had the righting reflex; head circle movements were detected in $20.5 \%$ of the animals; eye movements were observed in $32.4 \%$ of the piglets and in 1 finishing pig; $14.7 \%$ of the piglets showed the corneal reflex. The eye vibration (nystagmus) was observed in two pigs and uncoordinated kicking of hind legs was present in all the animals. Vocalizations were detected in $17.6 \%$ of piglets and rhythmic breathing observed in $35.3 \%$, especially in piglets. The interval between stunning and bleeding was always below 15 ", but ten piglets were fully conscious during bleeding. Moreover, for $61.8 \%$ of the uncorrected practices were carried out while hanging live animals by the hough.

\section{Pig carcass evaluation}

Carcass pH at 1 (pH1) and 24 (pH24) hours after slaughtering - $\mathrm{pH} 1$ and $\mathrm{pH} 24$ mean values of piglets and finishing pigs are showed in Table 1 . The $\mathrm{pH} 1$ mean value of piglet carcasses was $6.21 \pm 0.25$. pH24 mean values of piglets carcasses was $5.66 \pm 0.17$. It is important to highlight that the mean $\mathrm{pH}$ value of piglets carcasses slaughtered at agritourism 
A3 (pH1 6.51 $\pm 0.27 ; \mathrm{pH} 246.06 \pm 0.22)$ were not in accordance with those considered normal for swine (Hui et al., 2001). In this case, a long waiting time inside the wagons (30') and some difficulties to restraint and stunning the piglets could be caused an irregular dynamic of pH. Finishing pigs' carcasses $\mathrm{pH}$, evaluated at A3 and A6, showed a regular dynamic.

Mean ACC and EB levels $\left(\log _{10} \mathrm{CFU} / \mathrm{cm}^{2}\right)$ of piglets and finishing pigs carcasses are showed in Table 2. As regard piglets' carcasses, ACC prevalence was $100 \%$ with mean levels of $4.11 \pm 0.64$. Mean ACC levels of finishing pigs carcasses were $4.63 \pm 0.42$. Unhomogeneous contamination $(\mathrm{P}<0.5)$ was observed between agritourisms and between carcasses both for piglets and adult pigs. As regard EB results, piglet carcasses showed a prevalence of $81.6 \%$ with a mean contamination level of $2.55 \pm 0.80$. In finishing pig carcasses a prevalence of $100 \%$ and a mean level of $3.22 \pm 0.90$ were observed. Salmonella spp. and L.monocytogenes were not detected in any of the samples.

\section{Discussion}

Structural requirements of outbuilding slaughterhouses in agritourisms are suitable to produce meat in compliance with hygienic rules, considering the low risk level associated to these productions (low capacity, small amount of meat and very local distribution).

As said, operators were not trained as regard the rules laid down in Reg. CE 1099/2009 (European Commission, 2009). As a consequence, in many cases, handling and stunning procedures were not in compliance

Table 1. Results of carcass $\mathrm{pH}$ evaluation of piglets and finishing pigs, at 1 and 24 hours after slaughtering.

\begin{tabular}{lcc} 
& Piglets & Finishing pigs \\
$\mathrm{pH} 1$ & $6.21 \pm 0.25$ & $6.18 \pm 0.22$ \\
$\mathrm{pH} 24$ & $5.66 \pm 0.17$ & $5.49 \pm 0.11$ \\
\hline pH1, $\mathrm{pH}$ at $1 \mathrm{~h}$ after slaughtering; $\mathrm{pH} 24, \mathrm{pH}$ at $24 \mathrm{~h}$ after slaughtering. \\
\multicolumn{2}{l}{ Values are presented as mean \pm standard deviation. }
\end{tabular}

$\mathrm{pH}, \mathrm{pH}$ at $\mathrm{h}$ after slaughtering; $\mathrm{pH} 24, \mathrm{pH}$ at $24 \mathrm{~h}$ alues are presented as mean \pm standard deviation.
Valu

Table 2. Total viable count and Enterobacteriaceae in piglets and finishing pigs carcass surface.

\begin{tabular}{lcc} 
& Piglets & Finishing pigs \\
ACC & $4.11 \pm 0.64(100)$ & $4.63 \pm 0.42(100)$ \\
EB & $2.55 \pm 0.80(81.6)$ & $3.22 \pm 0.90(100)$ \\
\hline
\end{tabular}

ACC, aerobic colony count; EB, Enterobacteriaceae. Values are presented as $\log 10 \mathrm{CFU} / \mathrm{cm}^{2}$ mean \pm standard deviation, while values in brackets represent prevalence (\%). with animal welfare requirements set out in the above-mentioned Regulation. As said, $22 \%$ of the animals had not individual access to stunning and therefore the vision of the operations was not prevented. Electrodes were not applied in the correct position in $23.5 \%$ of the animals and repeated shocks had to be applied. Moreover, in a variable percentage of animals, stunning was not effective as demonstrated by the detection of consciousness signs as corneal reflex, head circle movements and breathing.

As regard results on carcass contamination, EB levels of finishing pigs carcasses were not in compliance with performance criteria of Reg. (EC) 2073/2005 (European Commission, 2005) and ACC showed high mean levels, thus highlighting lacking in slaughter hygienic conditions. AAC levels are higher than those detected by Bolton et al. (2002) that, in a smallscale slaughterhouse in finishing pigs carcasses, registered level accounting between 4.5 and $4.7 \mathrm{log}$. In Switzerland, Zweifel et al. (2008) detected mean counts of $3.3 \mathrm{log}$. In a study conducted at pig slaughterhouses in Sardinia, AAC mean counts of piglets carcass surfaces ranged from 4.6 and 5.7, and from 4.6 and 5.9 for finishing pigs (data not showed). The AAC levels indicate that a detailed analysis of the slaughtering process, including microbiological data, is necessary, considering that carcasses may be contaminated despite the absence of visible contamination (Arguello et al., 2013).

\section{Conclusions}

Appropriate measures must be adopted to improve animal welfare, such as correct handling of animals before stunning, correct application of electrodes, monitoring of effectiveness of stunning. Therefore, training of personnel on animal welfare is essential, other than compulsory as set out by Reg. 1099/2009, to improve handling and stunning procedures in agritourism slaughtering.

\section{References}

Arguello H, Carvajal A, Collazos JA, GarcíaFeliz C, Rubio P, 2013. Prevalence and serovars of Salmonella enterica on pig carcasses, slaughtered pigs and the environment of four Spanish slaughterhouses. Food Res Int 45:905-12.

Bolton DJ, Pearce RA, Sheridan JJ, Blair IS, McDowell DA, Harrington D, 2002. Washing and chilling as critical control points in pork slaughter hazard analysis and critical control point (HACCP) systems. J Appl Microbiol 92:893-902.

EFSA, 2013. Scientific opinion on monitoring procedures at slaughterhouses for bovines. EFSA J 11:3460.

European Commission, 2004a. Regulation on the hygiene of foodstuffs, 852/2004/EC. In: Official Journal, L 139:54.

European Commission, 2004b. Regulation laying down specific hygiene rules for the hygiene of foodstuffs, 853/2004/EC. In: Official Journal, L 139:55.

European Commission, 2005. Regulation of 15 November 2005 on microbiological criteria for foodstuffs, 2073/2005/EC. In: Official Journal, L 338, pp 1-26.

European Commission, 2009. Regulation on the protection of animals at the time of killing, 1099/2009/EC. In: Official Journal, L 303 , pp 1-30.

European Commission, 2013. Regulation 1305/2013/EC on support for rural development by the European Agricultural Fund for Rural Development (EAFRD) and repealing Council Regulation (EC) No 1698/2005. In: Official Journal, L 347, pp 487-548.

Grandin T, 2013. Recommended animal handling guidelines \& audit guide: a systematic approach to animal welfare. Available from: http://animalhandling.org/ht/a/Get DocumentAction/i/93003

Hui YH, Nip WK, Rogers RW, Young OA, 2001. Meat science and applications. Marcel Dekker Inc., New York, NY, USA.

ISO, 1996. Microbiology of food and animal feeding stuffs. Horizontal method for the detection and enumeration of Listeria monocytogenes. Part 1: detection method. ISO Norm 11290-1:1996. International Organization for Standardization Publ., Geneva, Switzerland.

ISO, 1998. Microbiology of food and animal feeding stuffs. Horizontal method for the detection and enumeration of Listeria monocytogenes. Part 2: enumeration method. ISO Norm 11290-2. International Organization for Standardization Publ., Geneva, Switzerland.

ISO, 2002. Microbiology of food and animal feeding stuffs. Horizontal method for the detection of Salmonella spp. ISO Norm 6579:2002. International Organization for Standardization Publ., Geneva, Switzerland.

ISO, 2003a. Microbiology of food and animal feeding stuffs: horizontal method for the enumeration of microorganisms. Colonycount technique at $30^{\circ} \mathrm{C}$. ISO Norm 4833:2003. International Organization for Standardization Publ., Geneva, Switzerland.

ISO, 2003b. Microbiology of the food chain. Carcass sampling for microbiological analysis. ISO/FDIS Norm 17604. International Organization for Standardization Publ., Geneva, Switzerland. 
ISO, 2004. Microbiology of food and animal feeding stuffs. Horizontal methods for the detection and enumeration of Enterobacteriaceae. Part 2: colony-count method. ISO Norm 21528-2:2004. International Organization for Standardization Publ., Geneva, Switzerland.

Italian Republic, 2006. Regulation n. 96. Available (in Italian) from: http://www.camera.it/parlam/leggi/06096l. htm

$\& c=72 \& s=1 \&$ file $=1998018$

McDowell, S.W., Porter, R., Madden, R., Cooper, B., Neill, S.D., 2007. Salmonella in slaughter pigs in Northern Ireland: prevalence and use of statistical modelling to investigate sample and abattoir effects. Int J Food Microbiol 118:116-25.

Sardinia Region, 1998. Regulation n. 18 of 23 June 1998. Available (in Italian) from: http://www.regione.sardegna.it/j/v/86?v=9
Sejian V, Lakritz J, Ezeji T, Lal R, 2011. Assessment methods and indicators of animal welfare. Asian J Anim Vet Adv 6:301-15.

Zweifel C, Fischer R, Stephan R, 2008. Microbiological contamination of pig and cattle carcasses in different small-scale Swiss abattoirs. Meat Sci 78:225-31. 